\title{
GAMBARAN SUMBER INFORMASI PHBS PADA KADER KESEHATAN
}

\author{
Source Information Of Phbs On Health Carder \\ Cecep Eli Kosasih' ${ }^{1}$, Tetti Solehati ${ }^{2}$, Agus Rahmat ${ }^{3}$ \\ 1,2 Faculty of Nursing UNPAD \\ ${ }^{3}$ Faculty of Communication UNPAD \\ Email: ek_cecep@yahoo.co.id
}

\begin{abstract}
ABSTRAK
Desa Pangandaran merupakan salah satu tempat wisata di Jawa Barat memiliki visi menjadi Desa Sehat. Sayangnya kesadaran ber-PHBS masyarakat Pangandaran masih rendah menyebabkan tingginya angka diare dan kecacingan di daerah tersebut kemungkinan karena kurangnya mendapatkan informasi tentag PHBS. Penelitian ini bertujuan untuk mengetahui sumber informasi PHBS pada kader kesehatan. Desain penelitian deskriptif kuantitatif. Penelitian dilakukan di Desa Pangandaran Kecamatan Pangandaran Jawa Barat. Populasi penelitian adalah semua kader kesehatan yang terdapat di Desa Pangandaran sejumlah 28 orang. Sample menggunakan total sampling. Instrumen yang digunakan adalah quisioner yang terdiri dari data karakteristik dan sumber informasi. Analisa yang digunakan deskriptif berupa frekuensi dan prosentase. Seluruh responden pernah mendapatkan informasi PHBS sejumlah 28 orang (100\%). Pada variabel genital hygiene diperoleh bahwa sebagian kecil responden mendapatkan informasi dari media cetak sejumlah 6 orang $(21,4 \%)$, hampir seluruh responden mendapatkan informasi dari petugas kesehatan sejumlah 24 orang $(85,7 \%)$. Pada variabel CTPS diperoleh bahwa seluruh responden pernah mendapatkan informasi 28 orang (100\%), hampir setengahnya responden mendapatkan informasi dari orang tua sejumlah 8 orang $(28,6 \%)$, sebagian kecil responden mendapatkan informasi dari saudara sejumlah 3 orang $(10,7 \%)$, sebagian kecil responden mendapatkan informasi dari teman sejumlah 2 orang $(7,1 \%)$, hampir setengahnya responden mendapatkan informasi dari media sosial sejumlah 12 orang $(42,9 \%)$, hampir seluruh responden mendapatkan informasi dari petugas kesehatan sejumlah 23 orang $(82,1 \%)$. Kesimpulan: Seluruh responden mendapatkan informasi. Walaupun sumber informasi lebih banyak diperoleh dari petugas kesehatan dan media sosial namun masih ada informasi didapat dari teman. Perlu pendekatan yang lebih kreatif dalam pemberian informasi dari petugas kesehatan misalnya dengan menggunakan media sosial.
\end{abstract}

Kata Kunci : : Kader kesehatan, PHBS, sumber informasi

\section{ABSTRACT}

Pangandaran is one of the tourism destinations in West Java, which is visited by foreign and domestic tourists. Unfortunately the awareness of PHBS of Pangandaran community was still low causing high rate of diarrhea and worms in the area are probably due to lack of information about health hygienic behaviour (PHBS). the aim of the research was to know the source of information PHBS on health cadres. Quantitative descriptive research design was used. The study population was all the health cadres in Pangandaran Village were 28 people, Pangandaran Sub-district, West Java. Sample used total sampling. The instrument used quisioner consisting of characteristic data and information sources. The analysis used descriptive in the form of frequency and percentage. The result showed that all respondents have received PHBS information of 28 people (100\%). In hygiene genital variables it was found that a small percentage of respondents got information from printed media of 6 people $(21,4 \%)$, almost all respondents got hygiene health officer information of 24 people $(85,7 \%)$. In the variables of CTPS, it was found that all respondents had received information about 28 people (100\%), almost half of the respondents got information on the CTPS from the parents of 8 people (28.6\%), a small of the respondents got CTPS information from relatives of 3 people $(10(7,1 \%)$, almost half of the respondents get information from social media of 12 people (42,9\% a total of 23 people (82.1\%). Conclusion: all respondents got information. More sources of information are obtained from health workers and social media. However, there is respondents got information from their friends. Need a creative approach of giving information from health officer by using social media.

Keywords : : Health cadres, PHBS, resources

\begin{tabular}{lll}
\hline Sekretariat & \multicolumn{2}{l}{ Article History: } \\
Editorial: Kampus FKM UNISMUH PALU - Palu 94118, & $\Rightarrow$ & Received 6 Mei 2018 \\
$\quad$ Sulawesi Tengah, Indonesia & $\Rightarrow$ & Revised 15 Mei 2018 \\
Telp/HP: +6281245936241, Fax (0451) 425627 & $\Rightarrow$ & Accepted 1 Juni 2018 \\
E-mail: jurnal.mppki@gmail.com & $\Rightarrow$ & Available online 25 Juni 2018 \\
OJS: http://jurnal.unismuhpalu.ac.id/index.php/PJKM &
\end{tabular}




\section{PENDAHULUAN}

Pangandaran merupakan salah satu tempat wisata di Jawa Barat yang ramai dikunjungi wisatawan mancanegara maupun domestik yang memiliki visi untuk menjadi desa sehat (Pemerintah Daerah Kabupaten Pangandaran, 2017). Mobilisasi penduduk dan pengunjung di daerah wisata Pangandaran menjadikan Kecamatan Pangandaran rentan terhadap penularan penyakit menular (Prasetyowati, 2013). Ada 2 penyakit dominan pada masyarakat pangandaran, salah satunya adalah terkait dengan perilaku masyarakat dalam menerapkan PHBS.

Menurut Kepala BP3L Dinkes Kab Pangandaran kesadaran ber-PHBS masyarakat Pangandaran masih rendah. Hal tersebut menjadi penyebab tingginya angka diare dan kecacingan di daerah tersebut (https://www.radartasikmalaya.com). Di Pangandaran, aspek pariwisata yang berkembang saat ini masih terfokus pada pengembangan infrastruktur sarana dan prasarana pariwisata, belum memperhatikan dari segi aspek kesehatan. Study pendahuluan selama berada di Pantai Pangandaran tahun 2016-2017 dari aspek PHBS menemukan tidak adanya tempat untuk mencuci tangan di sepanjang pinggiran pantai ataupun pada fasilitas umum lainnya. Pada tempat wisata kuliner jarang ditemukan keran dan sabun cuci tangan. selain cuci tangan, para perempuan juga kurang memahami tentang genital hygine yang menyebabkan masalah pada area genital mereka. Mereka kurang memahami bahwa sebelum dan setelah cebok harus mencuci tangan serta masalah perawatan genital yang benar. hal tersebut dapat menyebabkan resiko tinggi terhadap infeksi reproduksi pada perempuan.

Hasil wawancara dengan Kepala BAPPEDA Kabupten Pangandaran diperoleh bahwa Pangandaran sedang mengejar capaian visinya untuk menjadi Pantai Wisata yang mendunia, oleh karena itu masalah PHBS yang sedang di canangkan oleh PEMKAB Pangandaran melalui GERMAS (gerakan Masyarakat Sehat) merupakan target yang harus dicapai dengan secepatnya.

Pembangunan kesehatan bertujuan untuk meningkatkan kesadaran, kemauan, dan kemampuan hidup sehat bagi setiap orang agar terwujud derajat kesehatan masyarakat yang setinggi-tingginya melalui kebijakan dan Visi Indonesia Sehat 2010 yang terdiri dari tiga pilar utama, yaitu: lingkungan sehat, pelayanan kesehatan bermutu adil dan merata, serta perilaku sehat. Untuk mendukung upaya peningkatan perilaku sehat ditetapkan visi nasional promosi kesehatan sesuai Keputusan Menteri Kesehatan RI. No. 1193/MENKES/SK/X/2004 yaitu "Perilaku Hidup Bersih dan Sehat (PHBS) 2010" (Depkes RI, 2004). PHBS merupakan sekumpulan perilaku yang dilakukan atas dasar kesadaran sebagai hasil pembelajaran yang menjadikan seseorang atau keluarga dapat menolong diri sendiri di bidang kesehatan dan berperan aktif dalam mewujudkan kesehatan masyarakatnya (Depkes RI, 2009). Ada beberapa Indikator PHBS antara lain cuci tangan pakai sabun (CTPS) dan personal hygiene (vaginal hygiene)

Riset Kesehatan Dasar (Riskesdas) Tahun 2007 mengungkapkan bahwa rumah tangga di Indonesia yang mempraktekan PHBS baru mencapai 38,7\%. Kurang sadarnya masyarakat akan pentingnya PHBS sering menimbulkan masalah kesehatan, seperti: infeksi reproduksi pada wanita, infeksi saluran kemih, diare, dan kecacingan. Hasil Riskesdas 2007 menunjukkan penyebab terbesar meninggalnya balita dan anak-anak Indonesia adalah penyakit diare. Mencuci tangan secara tepat dengan menggunakan sabun dapat mengurangi resiko penyakit diare sebesar 42 sampai 47 persen (UNICEF Indonesia, 2012). Selain itu CTPS dapat mencegah terjadinya kecacingan, baik pada anak maupun ibu hamil. Kecacingan pada anak akan menimbulkan gangguan gizi pada anak tersebut, sedangkan kecacingan pada ibu hamil dapat menyebabkan anemia secara tidak langsung, karena komponen nutrisi yang seharusnya digunakan untuk membentuk haemoglobin habis dimakan cacing, walaupun ibu tersebut minum tablet Fe secara teratur. Membasuh organ kelamin yang benar dari arah depan (alat kelamin) ke belakang (anus) ditambah dengan CTPS sebelum dan sesudah BAB dan BAK juga dapat mencegah terjadinya infeksi pada saluran perkermihan dan reproduksi wanita secara tidak langsung. Hal ini dilakukan agar mengurangi masuknya bakteri dari daerah 
anus ke area saluran kencing dan saluran reproduksi wanita. Sayangnya masih banyak masyarakat Indonesia yang kurang sadar akan pentingnya mencuci tangan. Prevalensi nasional berperilaku benar dalam cuci tangan adalah 23,2\%. Salah satu kabupaten yang bermasalah dalam PHBS adalah Pangandaran. Hasil wawancara dengan Kepala Desa Pangandaran menyatakan bahwa desa ini sering terkena banjir akibat sungai Citanduy yang menguap saat musim hujan yang akhirnya menyebabkan penduduknya kekurangan air bersih, terkena ISPA, diare, dan gatal-gatal pada kulit. Data Puskesmas Pangandaran (2016) diperoleh bahwa penyakit ISPA dan diare merupakan penyakit yang masih tinggi.

Lokasi penelitian dilakukan di Desa Pangandaran Kecamatan Pangandaran Kabupaten Pangandaran karena kejadian kesakitan akibat perilaku PHBS yang kurang mendukung. Hal ini dimungkinkan karena kurangnya sumber informasi yang memadai. Sumber informasi diperlukan bagi masyarakat, baik dari petugas kesehatan, media sosial, maupun kader kesehatan. Sayangnya jumlah petugas kesehatan yang kurang memadai sering menjadikan masalah untuk memberikan informasi kesehatan pada masyarakat. Oleh karena itu diperlukan orang yang dapat menjadi perpanjangan tugas dari petugas kesehatan yang cerdas, terampil, memahami masalah serta dapat memecahkannya. Mereka adalah kader kesehatan posyandu. Para kader kesehatan ini bias diandalkan untuk membantu petugas kesehatan dalam memberikan informasi kesehatan pada masyarakat. Oleh karena itu mereka harus mendapatkan pengetahuan yang baik dan memadai. Seringkali para kader kesehatan ini ditemukan kurang memahami tentang materi kesehatan, salah satunya adalah PHBS tentang cuci tangan pakai sabun CTPS) dan genital hygiene. Oleh karena itu diperlukan penelitian tentang sumber informasi PHBS yang mereka peroleh.

\section{METODE PENELITIAN}

Desain penelitian deskriptif kuantitatif. Penelitian dilakukan di Desa Pangandaran Kecamatan Pangandaran Jawa Barat. Populasi penelitian adalah semua kader kesehatan yang terdapat di Desa Pangandaran sejumlah 28 orang. Sample menggunakan total sam- pling. Instrumen yang digunakan adalah quisioner yang terdiri dari dua yaitu (A) data karakteristik responden dan (B) sumber informasi. Analisa yang digunakan dalam penelitian ini adalah analisa deskriftif berupa frekuensi dan prosentase.

\section{HASIL}

Tabel 1. Distribusi Frekwensi Karakteristik Kader Kesehatan Posyandu ( $n=$ 28)

\begin{tabular}{lcc}
\hline Karakteristik & $\boldsymbol{f}$ & $\boldsymbol{\%}$ \\
\hline Suku & 13 & 46,4 \\
$\quad$ Sunda & 15 & 53,6 \\
Jawa & & \\
Agama & 28 & 100 \\
$\quad$ Islam & 0 & 0 \\
$\quad$ Lainnya & & \\
Pendidikan & 1 & 3,6 \\
$\quad$ Tidak & & \\
sekolah & 22 & 78,6 \\
SMP & 4 & 14,3 \\
$\quad$ SMA & 1 & 3,6 \\
PT & & \\
Pekerjaan & & 17,9 \\
IRT & 5 & 28,6 \\
Buruh & 8 & 25,0 \\
Wiraswasta & 7 & 28,6 \\
Lainnya & 8 &
\end{tabular}

Sumber,: Data primer, 2017

Terlihat dari tabel diatas, sebagian besar responden bersuku jawa sejumlah 15 orang $(53,6 \%)$, seluruh responden beragama Islam sejumlah orang $28(100 \%)$, hampir seluruh responden berpendidikan SMP sejumlah 22 orang $(78,6 \%)$, hampir setengahnya responden bekerja sebagai buruh dan lainnya masing-masing sejumlah 8 orang $(28,6 \%)$.

Tabel 2 menjelaskan seluruh responden yang pernah mendapatkan informasi PHBS sejumlah 28 orang (100\%). Pada variabel genital hygiene diperoleh bahwa sebagian kecil responden mendapatkan informasi dari media cetak sejumlah 6 
orang (21,4\%), hampir seluruh responden mendapatkan informasi genital hygiene petugas kesehatan sejumlah 24 orang $(85,7 \%)$.

Tabel 2. Distribusi Sumber Informasi PHBS Pada Kader Kesehatan Posyandu

\begin{tabular}{|c|c|c|}
\hline Karakteristik & $f$ & $\%$ \\
\hline \multicolumn{3}{|l|}{ Informasi } \\
\hline Ya & 28 & 100 \\
\hline Tidak & 0 & 0 \\
\hline \multicolumn{3}{|c|}{$\begin{array}{l}\text { Informasi genital hy- } \\
\text { giene melalui media } \\
\text { cetak }\end{array}$} \\
\hline Tidak & 22 & 78,6 \\
\hline Ya & 6 & 21,4 \\
\hline \multicolumn{3}{|c|}{$\begin{array}{l}\text { Informasi genital hy- } \\
\text { giene melalui petu- } \\
\text { gas kesehatan }\end{array}$} \\
\hline Tidak & 4 & 14,3 \\
\hline $\mathrm{Ya}$ & 24 & 85,7 \\
\hline \multicolumn{3}{|l|}{ Fasilitatas CTPS } \\
\hline Ya & 28 & 100 \\
\hline Tidak & 0 & 0 \\
\hline \multicolumn{3}{|l|}{ Informasi CTPS } \\
\hline ya & 28 & 100 \\
\hline Tidak & 0 & 0 \\
\hline \multicolumn{3}{|c|}{$\begin{array}{l}\text { Informasi CTPS dari } \\
\text { orang tua }\end{array}$} \\
\hline Tidak & 20 & 71,4 \\
\hline Ya & 8 & 28,6 \\
\hline \multicolumn{3}{|c|}{$\begin{array}{l}\text { Informasi CTPS dari } \\
\text { saudara }\end{array}$} \\
\hline Tidak & 25 & 89,3 \\
\hline Ya & 3 & 10,7 \\
\hline \multicolumn{3}{|c|}{$\begin{array}{l}\text { Informasi CTPS dari } \\
\text { teman }\end{array}$} \\
\hline Tidak & 26 & 92,9 \\
\hline Ya & 2 & 7,1 \\
\hline \multicolumn{3}{|c|}{$\begin{array}{l}\text { Informasi CTPS dari } \\
\text { media sosial }\end{array}$} \\
\hline Tidak & 16 & 57,1 \\
\hline Ya & 12 & 42,9 \\
\hline \multicolumn{3}{|c|}{$\begin{array}{l}\text { Informasi CTPS dari } \\
\text { media cetak }\end{array}$} \\
\hline Tidak & 23 & 82,1 \\
\hline Ya & 5 & 17,9 \\
\hline \multicolumn{3}{|c|}{$\begin{array}{l}\text { Informasi CTPS dari } \\
\text { petugas kesehatan }\end{array}$} \\
\hline Tidak & 5 & 17,9 \\
\hline Ya & 23 & 82,1 \\
\hline
\end{tabular}

Sumber: Data primer, 2017
Pada variabel CTPS diperoleh bahwa seluruh responden memiliki fasilitas CTPS di rumahnya sejumlah 28 orang $(100 \%)$, seluruh responden mendapatkan pernah informasi CTPS sejumlah 28 orang (100\%), hampir setengahnya responden mendapatkan informasi CTPS dari orang tua sejumlah 8 orang $(28,6 \%)$, sebagian kecil responden mendapatkan informasi CTPS dari saudara sejumlah 3 orang $(10,7 \%)$, sebagian kecil responden mendapatkan informasi CTPS dari teman sejumlah 2 orang $(7,1 \%)$, hampir setengahnya responden mendapatkan informasi CTPS dari media social sejumlah 12 orang $(42,9 \%)$, hampir seluruh responden mendapatkan informasi CTPS dari petugas kesehatan sejumlah 23 orang $(82,1 \%)$.

\section{PEMBAHASAN}

Pada kader kesehatan sudah melakukan PHBS dengan baik terutama pola CTPS dalam kehidupan sehari-harinya, tetapi pada masyarakatnya masih melakukan pola perilaku yang kurang sehat seperti jarang melakukan CTPS serta genital hygiene yang masih kurang di perhatikan. Padahal pemerintah sedang menggalakan program peningkatan perilaku hidup sehat (PHBS) sesuai dengan Kebijakan Nasional Promosi kesehatan yang menetapkan tiga strategi dasar promosi kesehatan dan PHBS, (Kemenkes RI, 2011 \& Depkes RI, 2008). Oleh karena itu penting sekali kader kesehatan untuk mendapatkan sumber informasi yang memadai.

Berdasarkan hasil penelitian diperoleh bahwa semua kader memperoleh informasi tentang PHBS. Pada variabel genital hygiene diperoleh bahwa sebagian kecil responden mendapatkan informasi dari media cetak sejumlah 6 orang $(21,4 \%)$, hampir seluruh responden mendapatkan informasi genital hygiene petugas kesehatan sejumlah 24 orang $(85,7 \%)$. Pada variabel CTPS diperoleh bahwa seluruh responden memiliki fasilitas CTPS di rumahnya sejumlah 28 orang $(100 \%)$, seluruh responden mendapatkan pernah informasi CTPS sejumlah 28 orang (100\%), hampir setengahnya responden mendapatkan informasi CTPS dari orang tua sejumlah 8 orang $(28,6 \%)$, sebagian kecil responden mendapatkan informasi CTPS dari saudara sejumlah 3 orang $(10,7 \%)$, sebagian kecil responden mendapatkan informasi CTPS 
dari teman sejumlah 2 orang $(7,1 \%)$, hampir setengahnya responden mendapatkan informasi CTPS dari media sosial sejumlah 12 orang $(42,9 \%)$, hamper seluruh responden mendapatkan informasi CTPS dari petugas kesehatan sejumlah 23 orang $(82,1 \%)$.

Kondisi kader kesehatan seperti itu menunjukan bahwa secara umum peserta merupakan kader yang aktif yang mengelola posyandu di wilayahnya masing-masing dan memilki rasa keingin tahuan yang tinggi dalam mengenal sesuatu dalam hal ini adalah ilmu kesehatan, karena mereka selalu terlibat dalam hal yang selama ini biasa mereka temukan. mereka berusaha mencari informasi baik dari kesehatan, media sosial, dan lainnya. Mereka seperti tidak mau ketinggalan informasi demi dapat membentu memecahkan masalah kesehatan di masyarakatnya. Bila di lihat dari karakteristik responden ditemukan bahwa hampir setengahnya responden bekerja sebagai buruh dan lainnya masing-masing sejumlah 8 orang $(28,6 \%)$, sehingga mereka lebih produktif dan memiliki motivasi untuk meningkatkan diri untukmencari informasi karena mereka memiliki banyak waktu luang. Hal ini akan berbeda kalau seandainya mereka adalah pekerja kantoran yang terikat dengan waktu jam kerja. Selain itu hampir seluruh responden berpendidikan SMP sejumlah 22orang $(78,6 \%)$. Orang dengan pendidikan SMP lumayan cukup memadai untuk mencari dan menerima informasi yang benar. Para kader seluruhnya beragama Islam sejumlah orang 28 (100\%). Hal ini juga merupakan sumber informasi dimana dalam agama Islam dikenal bahwa kebersihan adalah sebagian dari iman. bila dilihat dari sukunya, sebagian besar responden bersuku jawa sejumlah 15 orang $(53,6 \%)$. Suku Jawa terkenal dengan kegigihan dan motivasinya serta keingintahuan yang tinggi. Hal ini juga kemungkinan merupakan faktor perolehan sumber informasi pada kader kesehatan.

Kader kesehatan sebagai ujung tombak pelayanan dasar di desa menjadi penting artinya apabila pelaksanaan posyandu bisa berjalan dengan baik. Oleh karena itu diperlukan pemberian informasi yang memadai bagi tenaga kesehatan yang secara berkelanjutan khususnya PHBS. Dengan PHBS, masyarakat mampu mencegah dan menanggulangi masalah-masalah kesehatan
(Depkes R.I, 2007). Untuk bisa berkesinambungan hal-hal yang perlu dipertimbangkan adalah dukungan dari pihak puskesmas dalam bentuk dukungan pengetahuan dan operasional, sedangkan dari pemerintah desa berupa dukungan kebijakan dan operasional juga.

\section{KESIMPULAN DAN SARAN}

Seluruh responden mendapatkan informasi. Sumber informasi lebih banyak diperoleh dari petugas kesehatan dan media sosial. Perlu pendekatan yang lebih kreatif dalam pemberian informasi dari petugas kesehatan dengan menggunakan media sosial.

\section{DAFTAR PUSTAKA}

Departemen Kesehatan Republik Indonesia. (2004).Kebijakan Nasional Promosi Kesehatan: Keputusan Menteri Kesehatan Indonesia No 1193/ MENKES/SK/X/2004. Jakarta: Depkes R.I.

Departemen Kesehatan Republik Indonesia. (2007). Informasi Pengendalian Penyakit Menular dan Penyehatan Lingkungan.Jakarta: Depkes R.I.

Departemen Kesehatan Republik Indonesia.2009. Panduan Pembinaan dan Penilaian Perilaku Hidup Bersih dan Sehat di Rumah Tangga Melalui Tim Penggerak PKK.Jakarta:Depkes R.I.

Kementrian Kesehatan Republik Indonesia.2011. Pedoman Pembinaan Perilaku Hidup bersih dan Sehat (PHBS). Jakarta: Menteri Kesehatan RI.

Puskesmas Pangandaran. (2016). Laporan Tahunan Puskesmas Pangandaran Tahun 2016. Pangandaran: Dinas Kesehatan Kabupaten Pangandaran.

Pemerintah Daerah Kabupaten Pangandaran. 2017. Propil Pangandaran. Retrieved Mei 6, 2017, from http:// www.pangandarankab.go.id/profilpangandaran

Riskesdas. (2008). Riset Kesehatan Dasar 2007, Laporan Nasional 2007. Jakarta: Badan Penelitian dan Pengembangan Kesehatan Kemenkes RI.

Unicef Indonesia. (2012). Ringkasan Kajian:Air Bersih, Sanitasi, dan Kebersihan. Jakarta: Unicef Indonesia. 